\section{Dental practices encouraged to contribute to national survey}

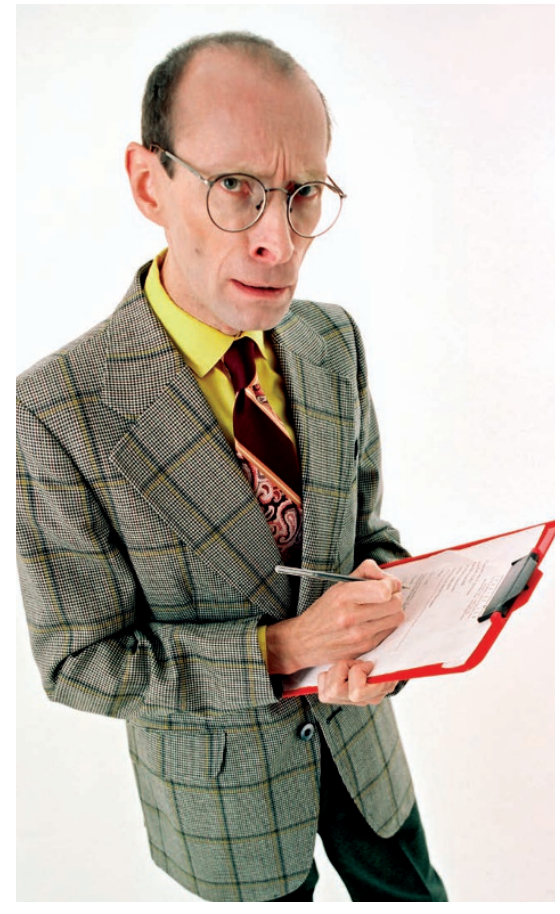

Public Health England (PHE) is conducting a national survey of oral health and service use among adults attending general dental practices.

The survey is designed to provide local level information on the oral health of this group of patients and their use of dental services, which will help commissioners to know:

- What the oral health needs of the adult population are

- Whether these needs are being met

- How best to commission services to meet the needs of adult patients.

The survey is designed to complement the national Adult Dental Health Survey that is carried out every ten years, and will involve a far larger sample of patients. The results will assist local authorities in monitoring health, overseeing provision of treatment services, formulating Joint Strategic Needs Assessments and oral health strategies. Inequalities in oral health will be described and the questionnaire could be used to compare information from sub-groups of the adult population which are of particular interest to individual local authorities.
Mohsan Ahmad of Oldham and Greater Manchester Local Dental Network has already taken part in the survey and said:

'We welcomed the adult oral health needs team into our practice and there was minimal disruption (I didn't know they were there until I saw them at lunch time). A member of their team approached patients in the waiting room to ask for their participation. Patients were happy to volunteer their time to be part of the survey.

'As a principal dentist in an area where our patients have varying oral health needs, it is really helpful to get a picture of this oral health need - not only in my area but also neighbouring areas and nationally. By practices welcoming the teams it will help with this assessment and future commissioning of NHS dental services. I would encourage dental practices to volunteer to be part of this essential process.

Each sampled dental practice that takes part in the survey is being asked to host their local fieldwork team (one interviewer/recorder and one trained epidemiology clinician) for a day or two half days or equivalent. Clinicians should be assured that all the information produced will be anonymised at patient, performer and practice level and therefore cannot be used for performance management.

For those practices which are randomly selected and agree to participate, there will be potential for feedback to the practice in the form of an audit which will entitle those participating to be certified for CPD.

Within each local authority there will be a requirement for a minimum of 160 adults to be surveyed, drawn from a minimum of ten general dental practices.

All participating practices, whether NHS or private, are eligible to claim an honorarium of 'no less than $£ 190$ ' to recognise the minor inconvenience to the practice. Practices will need to claim from their local Clinical Research Network, and should ask the visiting fieldwork team for further details.

Further detailed information can be found via http://bit.ly/2HyS1oH.

\section{New toothwear website launched}

A new website has been launched to help guide the public, dentists and their patients on erosive toothwear: www.erosivetoothwear.co.uk.

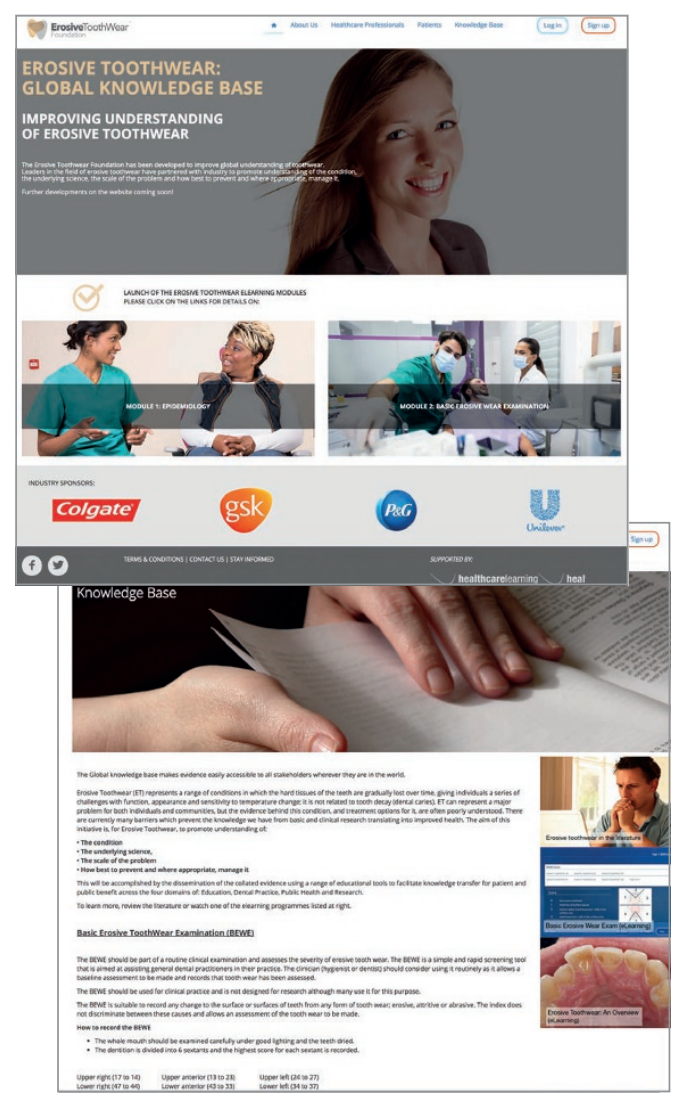

The website has been created by the Erosive Toothwear Foundation, a registered charity in England, and is financially supported by Colgate, GSK, Procter and Gamble and Unilever. The Foundation is jointly led by Professors Nigel Pitts and David Bartlett from King's College London's Dental Institute.

The new site has learning modules for dentists, guidance on literature and information for patients. It is designed to be userfriendly allowing visitors to the homepage to choose the appropriate learning guide to improve their knowledge and understanding of toothwear.

Professor David Bartlett is also guest editor of this special themed issue of the $B D J$ on toothwear (Volume 224, Issue 5).

Dentists are encouraged to promote the new website to their patients and to follow the links from the learning modules to gain CPD. 